\section{Homeopatia, medicina alternativa: entre contracultura, Nova Era e oficialização (Brasil, década de 1970)}

\section{Homeopathy, alternative medicine: between counterculture, the New Era, and formalization (Brazil, 1970s)}

\author{
Renata Palandri Sigolo ${ }^{i}$ \\ i Professora, Departamento de História/Centro de Filosofia \\ e Ciências Humanas/Universidade Federal de Santa Catarina. \\ Florianópolis - SC - Brasil \\ orcid.org/0000-0003-0007-7561 \\ r.palandri@ufsc.br
}

Recebido em 26 abr. 2018.

Aprovado em 3 ago. 2018
SIGOLO, Renata Palandri. Homeopatia, medicina alternativa: entre contracultura, Nova Era e oficialização (Brasil, década de 1970). História, Ciências, Saúde Manguinhos, Rio de Janeiro, v.26, n.4, out.-dez. 2019, p.1317-1335.

Resumo

$\mathrm{O}$ artigo analisa como a homeopatia foi veiculada ao público leigo no Brasil da década de 1970, período importante no processo de legitimação desse conhecimento como especialidade médica, o que ocorre em 1980. As fontes analisadas - compostas de artigos que circulavam no Jornal do Brasil e de livros destinados ao público leigo - permitem distinguir diferentes interlocutores que possuíam expectativas diversas diante da homeopatia, revelando um universo heterogêneo de compreensões e utilizações dessa medicina. Ao mesmo tempo, as fontes estabelecem um universo de representações envolvidas na construção da homeopatia como medicina alternativa, em que é perceptível sua relação com os movimentos de contracultura e Nova Era na formação de um "público consumidor de homeopatia".

Palavras-chave: história da homeopatia; medicinas alternativas; saúde; contracultura; Nova Era.

Abstract

The objective of this text is to analyze how homeopathy was conveyed to the lay public in Brazil during the 1970s, an important period in the process of legitimizing this practice as a medical specialty, which occurred in 1980. The sources analyzed (composed of articles that circulated in the Jornal do Brasil and books intended for the lay public) allow the reader to distinguish different interlocutors with various expectations of homeopathy, revealing a heterogeneous universe of understandings and uses for this medical system. At the same time, the sources establish a universe of representations present in the construction of homeopathy as alternative medicine, which is noticeable in its relationship with the counterculture movements and New Era in forming a "consuming public" for homeopathy.

Keywords: history of homeopathy; alternative medicine; health; counterculture; New Era. 


\section{Saúde, representações sociais e homeopatia}

A trajetória da homeopatia no Brasil foi profundamente marcada por estratégias de legitimação, que se transformaram de acordo com diferentes contextos. A análise desses enredos possibilita identificar as representações construídas acerca dessa medicina e permite entrever quais categorias e ideias sobre saúde e doença estavam em disputa. Quando investigamos o início do século XX, por exemplo, percebemos a luta da homeopatia institucional para se desvencilhar dos elementos religiosos que pudessem estar presentes tanto em sua doutrina como em sua prática. Esse movimento ocorre por meio da aliança com o positivismo e da luta pela inserção da medicina homeopática nas universidades. Durante o processo, foi importante a construção de representações sobre essa medicina junto ao público leigo, o que ocorreu principalmente por intermédio do debate entre homeopatas e médicos convencionais apresentado em jornais de grande circulação no país na primeira década do século XX (Sigolo, 2012).

O que vêm a ser representações sociais? Claudine Herzlich (2005) desenvolve sua análise a respeito do conceito pautada na ideia de que as concepções de saúde e doença formam um pensamento coletivo, rico e coerente, baseado na experiência pessoal do corpo. Da partilha de experiências nessa esfera nasce um "saber profano" sobre saúde e doença que, apesar de conectado, é independente do discurso médico acerca dessas categorias. Herzlich concebe as representações como construções dos sujeitos sempre em relação com a sociedade, dando sentido a suas ações e agindo no compartilhamento de suas concepções.

Em relação ao universo dos cuidados em saúde, ela afirma: "as representações da saúde e da doença devem ser consideradas, penso eu, como realidades sui generis, independentes dos conhecimentos médicos mesmo se deles elas se alimentam, e ultrapassando constantemente no plano do sentido e da orientação através da ação" (Herzlich, 2005, p.4). Assim, as representações sociais podem ser compreendidas como um conjunto de valores, concepções e práticas que têm como funções auxiliar o indivíduo a se orientar no ambiente social e assegurar a comunicação entre os membros de uma comunidade. Proporcionam a compreensão da diversidade e expressividade de todos os sistemas de conhecimento, possibilitando entender "como os saberes se encontram e se comunicam em esferas públicas" (Jovchelovitch, 2011, p.26).

A história da homeopatia no Brasil revela encontros e embates entre saberes de cura. Ainda na Europa, onde foi construída pelo médico alemão Samuel Hahnemann, essa medicina foi objeto de apropriações, reconstruções e alianças (Faure, 2002-2003). No Brasil de meados do século XIX, sua introdução foi marcada por aproximações alternadas entre catolicismo, espiritismo e positivismo, em um processo de intenso debate e, principalmente, embate com a biomedicina, tendo como porta-vozes instituições importantes, como o Instituto Hahnemanniano do Brasil (Sigolo, 2012).

De forma específica, a análise da década de 1970 permite compreender como as representações que envolvem a homeopatia foram construídas em um momento crucial de sua busca por legitimação por meio do reconhecimento como especialidade médica, que acaba por ocorrer em 1980. Madel Luz (1996) apresenta esse momento como um período em que os "generais da homeopatia", em uma estratégia coorporativa e por intermédio dos 
médicos Amaro Azevedo e Alberto Soares de Meirelles, representantes da Federação Brasileira de Homeopatia e do Instituto Hahnemanniano, lançaram esforços que, em um primeiro momento, revelaram-se infrutíferos. No âmbito acadêmico, destaca-se a atuação do movimento estudantil das faculdades de medicina em prol da defesa da homeopatia, com os Encontros Científicos dos Estudantes de Medicina (Ecem) e o Encontro Nacional dos Estudantes Interessados em Homeopatia (Eneih), ocorridos na década de 1970 (Luz, 1996, p.297).

Ainda segundo Madel Luz (1996), a década de 1970 foi um período considerado de recuperação das atividades da homeopatia, após uma suposta lacuna iniciada em 1930. Porém, não é possível sustentar essa hipótese se observarmos que outros autores apontam ações frutíferas de instituições homeopáticas no Brasil durante esse período. Um estudo sobre a presença da homeopatia na cidade de Santos relata a fundação, em 1959, do Laboratório Almeida Prado pelos farmacêuticos Almeida Prado e Rubens Gimenes, entre outras iniciativas em esferas distintas, como a assistência oferecida por instituições espíritas (Justo, Gomes, 2007, p.1164). Outra pesquisa revela a intensa movimentação da Liga Homeopática do Rio Grande do Sul nos anos 1940 e 1950. A liga foi, aliás, responsável pela edição e circulação do Boletim de Homeopatia, posteriormente denominado Revista de Homeopatia, entre 1941 e 1963. A autora, Beatriz Weber (2011), analisa várias iniciativas de organização da homeopatia em diversas partes do país entre os anos 1920 e 1950.

A valorização da homeopatia na década de 1970 teria sido alimentada pelo surgimento de outras "vontades" de conceber o mundo e viver nele, desenvolvidas pelos movimentos de contracultura, que também ocorreram nos EUA e na Europa. Esse é o contexto de análise deste texto, que pretende entender as representações acerca da homeopatia direcionadas e construídas a partir de algumas obras e de um jornal destinados ao público não médico ou leigo. Por meio da compreensão dessas fontes, pretende-se entender algumas das estratégias de inserção da medicina homeopática e como esta conseguiu a adesão de um público específico de usuários.

\section{Medicinas alternativas no contexto da contracultura}

Para se ter uma visão ampla da construção da homeopatia no período proposto (década de 1970), é preciso compreender a ascensão das "medicinas alternativas" em um movimento mais global que não envolve apenas as práticas de saúde. Diferentes autores (Luz, 1996, p.273; Queiroz, 2003, p.117; Barros, 2000, p.69) apontam esse contexto como importante para a reafirmação da homeopatia e é preciso compreender suas especificidades em território brasileiro, relacionando-as com o amplo cenário mundial. Para tanto, adentraremos brevemente o universo da contracultura brasileira, para depois pensar como o Brasil participou das buscas e ofertas de práticas de saúde no período.

A memória do movimento de contracultura no Brasil sofreu um apagamento diante da historiografia preocupada em reconstruir a resistência estudantil à ditadura civil-militar brasileira nos anos de 1964 a 1985, a ponto de entender esse movimento como menos importante e até mesmo como tendo sido causado pelo regime. Segundo Antônio Risério, "ao contrário do que se chegou a proclamar, a contracultura se expandiu no Brasil não 'por causa', mas 'apesar' da ditadura" (Risério et al., 2005, p.26). 
As manifestações contraculturais foram rotuladas como "desbunde", em um contexto que entendia a necessidade de se contrapor à ditadura militar e via somente na luta da esquerda tradicional essa possibilidade. O termo, forjado pela guerrilha brasileira, é originário da palavra "bunda", que possui, na maior parte das vezes, uma conotação negativa e relacionada à homossexualidade. O conceito era utilizado para descrever um comportamento irreverente, conectado a ideias de "alegre recusa, lúdico prazer, aventura pessoal, liberdade" (Dunn, 2016, p.38-39).

O comportamento contracultural ou "desbunde" era considerado incompatível com a mobilização de esquerda: os grupos armados expulsavam seus componentes condenados por comportamentos "desbundados", como fumar maconha ou mesmo frequentar grupos que eram rotulados como tais. A resistência ao regime militar, para os grupos da esquerda tradicional, não poderia admitir atitudes consideradas "alienadas", sendo que a expressão da subjetividade deveria ser reprimida (Almeida, Weiss, 1998).

O governo militar também olhava com mais do que reprovação para os grupos que manifestavam comportamentos relacionados à contracultura. Dunn (2016) aponta como o Departamento de Ordem Política e Social (Dops) aconselhava o monitoramento das atividades dos "andarilhos" considerados contrários à "segurança nacional". O movimento hippie era visto como uma ameaça ao modelo de trabalhador e de família que o regime militar se esforçava para construir, em um contexto em que as mudanças comportamentais se faziam sentir em escala global, pois não podemos ver a contracultura brasileira como uma manifestação isolada.

A palavra "contracultura" foi forjada por Theodore Roszak, atraído com especial atenção para os movimentos hippies e da nova esquerda estadunidense que, desacreditados com a esquerda tradicional e recusando a tecnocracia capitalista, se lançavam a formas alternativas de manifestação. Perplexo diante das manifestações que presenciava, ponderava: "na verdade, não parece exagero chamar de 'contracultura' aquele fenômeno que estamos vendo surgir entre os jovens. Ou seja, uma cultura tão radicalmente dissociada dos pressupostos básicos de nossa sociedade que muitas pessoas nem sequer a consideram uma cultura, e sim uma invasão bárbara de aspecto alarmante" (Roszak, 1972, p.54).

Caracterizar a contracultura a partir das especificidades locais, relacionando-as com o movimento global, é uma tarefa bastante vasta, mas uma particularidade fundamental do movimento é chave para compreendê-lo: a reabilitação da subjetividade como forma de compreensão e atuação do ser humano no mundo. Um intelectual que serviu de inspiração ao comportamento foi Herbert Marcuse, que teceu crítica contundente à sociedade tecnocrata do pós-guerra.

Marcuse denunciava a "sociedade afluente", em que a fantasia e a imaginação foram suplantadas pela razão: "a razão prevalece; torna-se desagradável mas útil e correta; a fantasia permanece agradável, mas torna-se inútil, inverídica - um mero jogo, divagação" (Marcuse, 2010, p.133). Porém, é a imaginação que pode restituir o "indivíduo total", aquele que está unido com os outros seres humanos e com uma experiência de passado na qual essa cisão não existia. A fantasia é apresentada como contendo uma função crítica indispensável, pois recusa os limites impostos pela sociedade tecnocrata baseada no princípio de desempenho. 
Nos movimentos de contracultura, é a "imaginação que está no poder", como afirmava um slogan do Maio de 68 francês. O movimento hippie, nascido na Califórnia, expressava essa busca pela fantasia por meio da psicodelia, seja como expressão artística (música, artes plásticas), no consumo de psicoativos, na realização de manifestações ou de hapennings, na forma de se vestir ou de se organizar em comunidades alternativas (Monneyron, Xiberras, 2008, p.187). No contexto brasileiro, retomando Christopher Dunn, esse movimento não ocorre na década de 1960 como nos EUA e na Europa, mas na década de 1970, logo após o Tropicalismo e em consonância com o surgimento de comunidades alternativas rurais e urbanas (Carvalho, 2008).

Um dos desdobramentos dos movimentos de contracultura emerge na década de 1980 com a fluida denominação de Nova Era, conceito de autoria desconhecida que sugere um momento de profundas alterações nas relações entre os seres humanos e entre estes e o meio ambiente. No Brasil, a denominação "Nova Era" é mais corrente a partir da década de 1980, mas já está presente na década anterior (D'Andrea, 2000). O título advém de um marco astrológico: o suposto término da Era de Peixes e início da Era de Aquário, marcado por uma série de transformações na sociedade.

A Era de Aquário inauguraria um período em que opostos entrariam em equilíbrio, como o objetivo e o subjetivo, a ciência e a religião, e na qual a construção das referências e concepções de mundo se tornava muito individualizada, com vistas à construção de um "self perfeito". A ideia de mudança, não se verificando em um nível macro, foi transferida para o micro, ou do sujeito, que via a revolução possível em mudanças de atitude individuais. Apesar de afetar diretamente as escolhas religiosas, o movimento Nova Era influenciou várias esferas da vida humana, incluída a saúde (D'Andrea, 2000, p.101).

\section{Contracultura, Nova Era e medicinas alternativas}

Qual a relação entre os movimentos contraculturais e da Nova Era e a emergência das medicinas alternativas? Em primeiro lugar, é preciso definir o que é medicina alternativa. Citando Sharma, João Tadeu de Andrade (2006, p.28), diferencia os termos "alternativo", "complementar" e "integrativo" e explica que o conceito de medicina alternativa pode estar relacionado a um posicionamento político-ideológico derivado de uma visão de mundo oposta à "sociedade moderna" e às concepções e métodos da biomedicina. Esse momento de questionamento, denominado também "crise" (Luz, 2000), é possível devido ao contexto mundial e nacional já explicitado, que levanta uma série de considerações globais que tem como alvo o universo das práticas de cura institucionalizadas.

Nesse momento de "crise", a biomedicina foi criticada por excluir a subjetividade do "ser que sofre" para privilegiar uma pretensa objetividade e neutralidade daquele que observa a doença, ou seja, do médico, reforçando a supremacia da tecnologia empregada para investigar a doença, e não o doente. Muitas vezes, a intervenção médica se tornava iatrogenia, e seus métodos provocavam a deterioração do relacionamento entre médico e "paciente". Essas características surgem desde ao menos fins do século XVIII (Queiroz, 2003), e se aprofundam após a Segunda Guerra Mundial, em um momento em que a biomedicina construía em torno de si a ideia de que era vitoriosa diante da "batalha" contra as doenças. 
O cenário mundial das instituições de saúde também favoreceu a emergência das medicinas alternativas. A Organização Mundial da Saúde (OMS) defendeu, a partir de 1976, a utilização de "práticas terapêuticas alternativas e não institucionalizadas pelo sistema de saúde" (Queiroz, 2003, p.21), posição renovada na Conferência de Alma Ata, em 1978. Simultaneamente, a OMS propôs um conceito de saúde que via o ser humano de forma mais integrada e defendeu uma medicina menos hospitalocêntrica. Também foi no âmbito dessa marcante conferência que a OMS estabeleceu os cuidados primários à saúde como essenciais e de acesso universal aos indivíduos, fazendo parte de seu primeiro contato com o sistema nacional de saúde (Lavras, 2011, p.869).

As políticas institucionais defensoras das medicinas alternativas, que pretendiam reduzir o custo e dar acesso à saúde, não necessariamente coincidiram com as escolhas e os objetivos em nível microscópico, em uma sociedade em que os indivíduos faziam amálgamas de acordo com suas concepções de saúde e doença. No caso daqueles que se identificavam com os ideais da contracultura e do movimento Nova Era, essas decisões eram tomadas levando em consideração a comunicação por meio de redes (Magnani, 1999) formadas de maneira muitas vezes efêmera, mas que proporcionavam a sociabilidade dos "alternativos".

Outra característica presente nos movimentos de contracultura e Nova Era, peculiar da alta modernidade inaugurada pelo período pós-Segunda Guerra Mundial, é a reflexividade (Giddens, 2002). ${ }^{1}$ A reflexividade é um atributo do período em que as certezas institucionais são substituídas por escolhas pessoais e fragmentadas, espelhadas pelo "projeto reflexivo do Eu": as pessoas já não possuem um padrão fechado de comportamento, mas constroem um estilo de vida baseado em escolhas, na dialética entre local e global e no cálculo dos riscos representados pelas decisões.

A "reflexividade do Eu", ou seja, as escolhas realizadas pelos indivíduos na construção de suas identidades, afeta o corpo e os processos psíquicos, sendo que seu controle e construção passam a ser um dos objetivos do indivíduo. O desenvolvimento, higidez e bem-estar do corpo tornam-se uma questão de escolhas e de adoção de estilos de vida. Também no âmbito das possibilidades, as decisões tomadas por meio de cálculo de riscos são realizadas por intermédio da confiança. Por exemplo, quando se escolhe um ou outro medicamento, o indivíduo o faz com base na confiança construída em relação à biomedicina ou à indústria farmacêutica, uma vez que ele acredita que a ação descrita de tal medicamento realmente ocorre em seu organismo.

As escolhas de estilo de vida suscitam questionamentos que são respondidos pelos "novos movimentos sociais" (Giddens, 2002, p.17), com a "política-vida", prática envolvida nas questões existenciais descartadas pelas instituições. Isto se relaciona à construção de um "novo sentido de identidade" próprio da alta modernidade, em que as relações pessoais apresentam mais oportunidades de autoexpressão, de forma diferenciada daquelas das sociedades tradicionais. Por serem mais arriscadas e perigosas, essas relações também geram mais ansiedade, que também provocam a mobilização de respostas que proporcionem a adaptabilidade do indivíduo. Desse modo, as escolhas fragmentadas e subjetivas podem ser vistas como um movimento de resistência a uma ordem dominante. 


\section{O papel da imprensa na divulgação da homeopatia}

No "circuito alternativo" - espaços de disseminação e circulação de ideias e produtos da contracultura e da Nova Era - onde essas escolhas eram feitas, a imprensa exerceu papel importante como veículo construtor e divulgador de representações sobre saúde e doença e, mais especificamente nesta análise, a respeito da homeopatia. Vários periódicos, editoras e livrarias surgiram na década de 1970 com o objetivo de publicar e divulgar temas relacionados ao mundo alternativo e que atendiam à demanda de conhecimento e informação por parte de um público que fazia suas escolhas dentro desse universo (Magnani, 2000, p.22-23).

As obras elencadas para a investigação das representações sobre a homeopatia foram publicadas por diferentes editoras brasileiras, em São Paulo e no Rio de Janeiro. O livro mais antigo selecionado para esta análise, de autoria do doutor Heinrich Weyke, intitula-se A cura pelas plantas, pela água e pela homeopatia e tem 139 páginas. Apesar de lançado em 1965, circulou também durante o período estudado. Foi publicado por Edições e Publicações Brasil, que na contracapa anunciava outros títulos passíveis de serem adquiridos pelo leitor, todos apresentados como "ciências ocultas". Entre eles figuravam o Livro dos sonhos, o Livro do feiticeiro e o lançamento Pontos cantados, riscados e oferendas.

Uma obra homônima, de autoria do professor Armando Seabra, foi publicada pelas Edições O Livreiro, de São Paulo. O livro contém 74 páginas e, apesar da ausência de data, é possível saber que só pode ter sido publicado antes de 1984, uma vez que o Jornal do Commercio anunciou a falência da editora em 15 de novembro daquele ano. Sobre $\mathrm{O}$ Livreiro foi possível saber que a editora era conhecida pela publicação de quadrinhos entre 1960 e $1970^{2}$ e que também publicou uma coleção de livros sobre esportes, que podiam ser adquiridos por correspondência (Sensacional..., 2 set. 1977).

Ao contrário dos outros autores das obras escolhidas cujas informações mais precisas não foram encontradas, o autor do terceiro título, o Livro de bolso da medicina natural, Márcio Bontempo é médico e possui diversas obras sobre medicina "alternativa e natural", publicadas dos anos 1970 até hoje. Ele mantém um blog de informações e notícias a respeito do tema. O livro foi lançado em 1979 com 176 páginas e teve várias reedições em anos posteriores pela Editora Ground. A editora iniciou suas atividades em 1973, com a publicação de um livro sobre do-in, e foi responsável pela divulgação de muitas obras que abordam o "modo de vida alternativo", existindo até os dias de hoje.

A última obra selecionada, o Guia de medicina alternativa, escrita por Donald Law, tem sua versão original em inglês datada de 1974, mas foi lançada em 1981. Apesar de a data não corresponder ao período estudado, o livro foi incluído na análise por oferecer um indicativo de apresentação da homeopatia que, ao que parece, foi recorrente na década de 1980 e traduz a ideia de "medicina alternativa". O livro tem 176 páginas e traz uma lista de sessenta possibilidades de diagnósticos e terapêuticas passíveis de ser classificados como "medicina alternativa" e as recomendações de utilização. Não possui uma "lista de doenças" como os demais e foi publicado pela Editora Brasiliense, ainda presente no mercado editorial brasileiro com um universo temático bastante eclético. 
Todos os livros analisados, com exceção do Guia de medicina alternativa, possuem explicações introdutórias sobre as medicinas que pretendem abordar e uma seção posterior, dedicada aos tratamentos. Estes são classificados por ordem alfabética em uma pequena enciclopédia, apresentando as doenças e seus sintomas ou definições, seguidas pelas terapêuticas aconselhadas, que abarcam a diversidade de medicinas selecionadas pelos autores.

O Jornal do Brasil, por sua vez, era publicado no Rio de Janeiro, local considerado o epicentro da contracultura brasileira (Dunn, 2016, p.47). Criado em 1891, o jornal fez oposição moderada ao governo do presidente Marechal Deodoro da Fonseca (1889-1891). Na década de 1950, participou do processo de modernização da imprensa brasileira, revelando a tendência de comunicar com objetividade, com a intenção de aparentar neutralidade. Já no início da década de 1970, passa por mudanças tanto no estilo gráfico quanto na forma de organizar a equipe de redação (Lima, 2006, p.21-31).

A transformação do Jornal do Brasil em fins da década de 1960 e início da década de 1970 deu origem ao suplemento Caderno B, criado com o objetivo de ser um espaço destinado às matérias de cultura e entretenimento. Por participar do contexto de mudança da capital do país para Brasília, o Caderno B pode representar a vontade de construir a imagem do Rio de Janeiro como capital cosmopolita (Lima, 2006, p.49).

Sabemos um pouco sobre o perfil de leitores do Jornal do Brasil por meio de pesquisa feita pelo próprio periódico em abril de 1972: a maior parte pertencia às classes "média" e "abastada" e estava na faixa entre 30 e 50 anos de idade, com ligeira vantagem para o público masculino. Em sua pesquisa, o jornal não esclareceu quais foram os critérios adotados para definir as classes sociais (Lima, 2006, p.133).

\section{O Jornal do Brasil e a circulação de representações sobre a homeopatia}

Antes de analisarmos as obras mais específicas destinadas a um público que buscava tratar e ser tratado pela homeopatia, é importante lançarmos um olhar sobre sua construção nas páginas do Jornal do Brasil. Durante o período, o periódico publicou pouco mais de quarenta matérias sobre homeopatia, sem contar os anúncios de médicos homeopatas constantes nos classificados.

Entre 1970 e 1974, foram constantes as notas anunciando cursos gratuitos para médicos, dentistas, veterinários, farmacêuticos e estudantes ofertados pela Federação Brasileira de Homeopatia, criada na década de 1930 no Rio de Janeiro como dissidência do Instituto Hahnemanniano do Brasil e voltada para a realização de eventos e cursos de especialização, entre outras atividades (Luz, 1996, p.57). Esses cursos revelam a preocupação em formar homeopatas entre os profissionais que já possuíam alguma habilitação acadêmica na área de saúde, cuidado que demonstra a vontade de construir uma identidade entre seus profissionais, a homeopatia e a ciência.

Essa primeira representação evocada - a da medicina homeopática como ciência - é recorrente nas páginas do Jornal do Brasil em diferentes circunstâncias. Nesse período, três situações que revelam essa preocupação são recorrentes nas matérias do periódico: o debate sobre a oficialização da homeopatia, o anúncio de congressos homeopáticos e o diálogo gerado durante o surto de meningite entre julho e agosto de 1974. 
O primeiro artigo que anunciava a luta dos homeopatas por reconhecimento ocupava metade de uma página do jornal, estampando uma foto da farmácia Teixeira de Novaes, com seu mobiliário e frascos centenários. O texto anunciava que uma oficialização prévia já havia ocorrido em 1918 e que chegara o momento de o Conselho Nacional de Educação consolidar a homeopatia como especialidade, diante da existência de $10 \%$ de médicos dentro do quadro profissional no Brasil que se declaravam homeopatas. Além dessas justificativas, apresentavam resultados de uma pesquisa feita em 1964, segundo a qual 73\% dos entrevistados eram favoráveis à homeopatia (Homeopatia..., 14 set. 1970.)

Ao esclarecer a homeopatia aos leitores, o periódico evocava o princípio dos semelhantes, assim explicado: "O mal se cura utilizando-se, no seu combate, o próprio mal. Isto é, dominase a doença empregando-se um remédio que seja tão mau quanto ela" (Homeopatia..., 14 set. 1970). É interessante notar que a descrição usa a concepção de doença da biomedicina para esclarecer o princípio do similibus, empregando uma metáfora bélica que define a doença como um elemento "mau" que precisa ser combatido, como uma entidade independente do organismo do doente.

Na sequência do mesmo artigo, revela-se a preocupação em representar as relações entre homeopatas e médicos convencionais como harmoniosas, gerando uma estreita ligação da homeopatia com a academia: "Os homeopatas acham que não se devem criar guerras nos dois campos, pois a medicina é uma só. Muitos se utilizam ainda dos dois métodos, isto é, a medicina homeopática e a alopática". Complementando a ideia, Amaro Azevedo, médico homeopata entrevistado pelo jornal, esclarecia que, apesar de ocorrer atrito entre homeopatas e médicos convencionais, "isto não é válido, pois tudo se baseia na bioquímica, que tanto nós homeopatas como os outros médicos somos obrigados a conhecer e a estudar" (Homeopatia..., 14 set. 1970). A base comum do curso médico seria a responsável por garantir cientificidade à homeopatia e por diluir quaisquer diferenças entre as escolas médicas.

Dois anos depois, outro artigo construía a urgência no desenvolvimento da homeopatia no país, a partir de seu título: "250 seria o número de homeopatas a atender 30 milhões de brasileiros" (Homeopatia..., 6 nov. 1972). Reclamando da falta de divulgação advinda da carência de apoio governamental, o médico entrevistado, Alfredo Di Vernieri, ressalta a história dessa medicina no Rio de Janeiro, local onde houve maior possibilidade de expansão. Ele lembra que a difusão da homeopatia seria mais eficaz com a realização de cursos de extensão universitários, principalmente destinados a médicos, e a ampliação dos fóruns de reunião científica, como os congressos.

Reconstruindo o discurso homeopático do início do século XX, declara:

a homeopatia é uma terapêutica positiva porque nós nos baseamos numa lei natural de cura, que é a 'lei dos semelhantes'. Todas as vezes que o médico faz o seu trabalho obedecendo esta lei, sempre tem bons resultados. Não é uma medicina especial, a diferença da ciência comum está na terapêutica, já que o estudo da patologia do doente é a mesma. Nós empregamos remédios que foram experimentados nas pessoas sãs e nelas provocaram sintomas que achamos no doente. O princípio da aplicação de uma vacina, que possui anticorpos, é essencial na homeopatia (Homeopatia..., 6 nov. 1972).

Di Vernieri retoma um discurso enunciado no início do século XX para aproximar a homeopatia do positivismo, estabelecendo o universo das leis como guia e apagando as 
diferenças com a biomedicina ao reduzi-las a uma "questão terapêutica". O estatuto de igualdade de pertencimento a uma mesma ciência era reclamado, lançando-se mão da vacina como exemplo de terapêutica de princípio homeopático adotada pela biomedicina.

Nesse mesmo mês de novembro de 1972, as esperanças em ser uma "especialidade normal" eram reavivadas pelo Jornal do Brasil (Homeopatia..., 23 nov. 1972). O artigo anunciava que entre as resoluções do $22^{\circ}$ Congresso Brasileiro de Homeopatia ocorrido no Rio de Janeiro figurava a solicitação, à Associação Médica Brasileira, de que a homeopatia fosse considerada uma das 41 especialidades médicas existentes, além da revogação de não obrigatoriedade da cadeira de homeopatia no curso da Escola de Medicina e Cirurgia do Rio de Janeiro. Outra expectativa do mesmo congresso era a assinatura de Mário Machado de Lemos, ministro da Saúde do Brasil entre 1972 e 1974, aprovando, na farmacopeia brasileira, uma relação de medicamentos homeopáticos (Homeopatia..., 18 nov. 1972). A espera por reconhecimento como "especialidade farmacológica e terapêutica" vai acompanhar a homeopatia até 1979, quando o $47^{\circ}$ Congresso Médico Homeopata Pan-americano é instalado com esse objetivo (Homeopatas..., 16 out. 1979).

Já no ano seguinte, os médicos convencionais anunciavam a presença de homeopatas em seu congresso, a fim de "dar uma oportunidade para que os médicos homeopatas - até então marginalizados na Associação Médica Brasileira (AMB) - apresentem as provas que prometeram de que a homeopatia tem um fundo científico e que seus estudos e teorias foram completamente atualizados" (Associação..., 8 out. 1973). Apesar de construir uma certa concórdia entre os pares com o convite, a AMB admitia segregar seus colegas e lançava um desafio que talvez os homeopatas não pudessem cumprir, uma vez que a avaliação de suas bases seria feita pela perspectiva da biomedicina.

A demanda por inserção no contexto da ciência também se dava por meio da conquista de espaço nos locais de atendimento dos serviços alopáticos. Em 1977, três médicos homeopatas e estudantes de medicina enviaram um pedido ao Ministério da Previdência e Assistência Social para que fosse feita a inclusão da homeopatia como especialidade nos serviços médicos. Ao mesmo tempo, outra moção fora encaminhada ao Ministério da Educação e Cultura para que a disciplina de homeopatia fosse incluída como matéria obrigatória dos cursos médicos (Previdência..., 9 out. 1977).

O artigo retomava o debate relativo à homeopatia como especialidade, explicando por que a demanda havia sido recusada pelo Ministério da Educação e Cultura, que via como desnecessário transformar em especialidade uma simples "opção de receitar". Já o médico homeopata entrevistado, Alfredo Eugenio Vervloet, ressaltava o fato de a homeopatia "não ser um tratamento que qualquer um pode receitar, mas um estudo, um aprofundamento, uma especialidade" (Previdência..., 9 out. 1977).

As posições diversas do que seria a homeopatia revelam quão complicada era sua aproximação com a biomedicina, tendo em vista sua legitimação. Apagar as diferenças entre ambas, para incluir a medicina de Hahnemann no universo científico reconhecido, poderia significar diminuir a importância de sua doutrina para reduzi-la a um método terapêutico. Isso ainda era reforçado pelas críticas à "agressividade da farmacoterapia acadêmica" e porque a homeopatia "já comprovou ser também uma terapia sem riscos" (Previdência..., 9 out. 1977). Essas imagens valorativas construídas pelos homeopatas 
também limitavam a visão do público da homeopatia como terapêutica em vez de sistema médico.

O terceiro principal momento em que os homeopatas têm a oportunidade de construir suas representações junto ao público leigo residiu em um contexto de crise de saúde, como em outros existentes na história da homeopatia brasileira. Nessa década, a epidemia de meningite de 1974 em São Paulo ofereceu o campo de disputa para ambos os sistemas médicos, e é perceptível a posição tomada por eles. A primeira reportagem sobre o assunto em que a homeopatia se pronuncia tratava da tentativa de fabricação de vacinas contra a meningite no país.

Em conjunto com os depoimentos do Instituto Vital Brasil sobre as pesquisas relativas à vacina e como seria produzida, havia o anúncio de que "em São Paulo, um grupo de homeopatas planeja produzir o nosódio meningococcinum, resultado da dinamização do líquido cérebro-espinhal contaminado, retirado de pacientes mortos pela doença". Apesar da descrição da "vacina homeopática" não parecer convidativa, aparentemente os medicamentos o eram. A matéria, que ocupa o centro da página, apresenta duas fotos: uma que retrata filas em farmácias na capital paulista, e a segunda que mostra três frascos de homeopatia Almeida Prado, contendo os específicos indicados para prevenir a meningite. Na continuidade da mesma reportagem, o depoimento do secretário da Saúde desacreditava a homeopatia ao dizer respeitar seus usuários mas, ao mesmo tempo, acreditar que o uso de "medicamentos não consagrados pela medicina é uma exploração do povo sem orientação" (Brasil..., 27 jul. 1974).

Na contramão da opinião do secretário, segundo o Jornal do Brasil, a Associação Paulista de Medicina, criada em 1930 e que teve, entre 1973 e 1977, como presidente o doutor Henrique Arouche de Toledo, dava liberdade aos médicos homeopatas para recomendar o medicamento "preventivo e curativo" da meningite, o Meningococcinum. A reportagem, vizinha de outras que ocupam a página em sua totalidade e anunciam números alarmantes e providências contra a doença, traz detalhes sobre a fabricação do medicamento, em um modelo que se aproxima da descrição repleta de termos técnicos apresentada pelo Instituto Vital Brasil para a fabricação da vacina.

Assim como a biomedicina, a homeopatia não se via privada do "avanço tecnológico" que proporcionava a fabricação de uma vacina ou medicamento, e a essa representação ainda se acrescentava a segurança de ausência de iatrogenia: "um século e meio de experiência em homeopatia, com resultados animadores com medicamentos contra outras doenças infecciosas nos dão boas perspectivas nessa nova tentativa, que não trará prejuízo nenhum ao organismo humano, pois não provoca efeitos colaterais", garantia a médica Helena Minin (Homeopatas..., 3 ago. 1974).

Em um mês de cobertura da epidemia de meningite em São Paulo, o Jornal do Brasil publicou sete reportagens que mostravam a presença da homeopatia no cenário da doença, principalmente por meio do grande aumento na procura de seus medicamentos ditos "preventivos" e na dúvida sobre a eficácia dos mesmos manifestada por médicos entrevistados. Sob a pressão da Secretaria de Saúde de São Paulo, a Associação Paulista de Medicina precisou se pronunciar a respeito da possível falta de registro dos medicamentos homeopáticos, afirmando que eram regulares uma vez que constavam da Farmacopeia Homeopática assinada havia dois anos pelo ministro da Saúde (Meningite..., 26 ago. 1974). 
Em meio a essas várias notícias, destaca-se a carta de um leitor do Rio de Janeiro que escreve ao periódico reclamando do preço dos medicamentos homeopáticos e, ao fazê-lo, apresenta as diferenças entre biomedicina e homeopatia:

a primeira, oficial, dispõe de laboratórios, centros de pesquisa, aperfeiçoado arsenal terapêutico etc. É uma medicina cada vez mais cara, que só estaria ao alcance dos ricos, não fosse a socialização que sofre gradativamente. Seu exercício é fiscalizado pelo Governo, inclusive no que se refere ao preço dos medicamentos. A segunda, a homeopatia, com suas 'aguinhas', devia atender as classes menos favorecidas, pois terapêutica sintomática não exige métodos propedêuticos caros e seus preços de consulta e de remédios deviam ser bem mais acessíveis aos desvalidos da fortuna. Infelizmente, isso já era (Ferreira, 3 ago. 1974).

A carta de Álvaro Ferreira apresenta mais uma das representações que foram construídas sobre a homeopatia: a de medicina barata destinada aos pobres. Esse adjetivo, em geral valorizado pelos homeopatas entrevistados em outras reportagens, é tomado aqui como deficiência diante da "outra medicina" que, com seu aparato, seria mais eficaz e serviria a uma elite. Duas referências podem estar presentes nessa representação: uma relacionada ao papel da homeopatia junto às classes pobres entre o final do século XIX e o início do XX, e outra relativa aos discursos emitidos pela OMS acerca da importância das medicinas de baixo custo em sociedades menos favorecidas economicamente. Aqui, com sua crítica, o leitor parece sinalizar uma possível mudança na clientela da medicina homeopática.

\section{Homeopatia: natural, contracultural}

Em paralelo ao discurso construído pelos homeopatas que, sobretudo com o suporte das instituições da categoria, como o Instituto Hahnemanniano, conectava a homeopatia à ciência por meio da proximidade com a academia e a biomedicina, outros tipos de representações foram construídas no mesmo jornal, em espaços específicos. Seções do Jornal do Brasil como Turismo, Comportamento e principalmente o suplemento Caderno B foram palcos privilegiados da elaboração de representações da homeopatia como medicina natural, alternativa e relacionada aos movimentos e grupos herdeiros da contracultura brasileira.

A "medicina das pequenas doses" é apresentada por esses espaços do Jornal do Brasil como fazendo parte ou dialogando com outras práticas também classificadas como "alternativas". Um grupo comunitário na Bahia, que geria um saveiro, um motel e um restaurante, relatava a ampliação deste último: "até setembro, um restaurante macrobiótico deverá estar funcionando no segundo andar da casa, local onde hoje são feitas as sessões de leitura e estudo de numerologia, telepatia, mentalização e homeopatia, porque, para Beto Bandeira, 'o estudo do espiritual é importante, já que a vida é composta de $60 \%$ do astral e o restante da matéria que existe por aí'” (Empresa..., 23 ago. 1973).

A combinação entre homeopatia e outras práticas alternativas também é apresentada em palestras que ocorriam em diversos espaços e eram anunciadas no Jornal do Brasil, como um ciclo de palestras sobre macrobiótica, acupuntura, ervas medicinais, homeopatia e ioga ofertado por uma loja do Rio de Janeiro (Cursos..., 26 maio 1979). Assim, a homeopatia pertenceria a um circuito que englobaria outras atitudes e crenças que se distinguiriam 
de outras culturalmente mais difundidas, formando grupos alternativos herdeiros da contracultura.

Outra característica, que também é explorada pelas representações mais institucionais da homeopatia, é a de medicina natural. $\mathrm{O}$ "retorno à natureza" é uma das características dos movimentos de contracultura e Nova Era, imersos no movimento ecológico que emergiu nas décadas de 1960 e 1970 (Queiroz, 2003). Em uma reportagem sobre agrobiologia, por exemplo, a homeopatia é tomada como metáfora. O artigo conta como a agrobiologia surgiu nos anos 1960 como forma de se contrapor à "Revolução Verde" que promoveu o uso de agrotóxicos na agricultura, e com a proposta de retornar a formas anteriores de produzir alimentos: "ou seja, trabalhar a terra por meios naturais, com preparados feitos à base de plantas, numa espécie de homeopatia voltada à terra" (Agrobiologia..., 23 abr. 1975).

No mesmo Caderno B, ocupando uma página inteira com fotos, Célia Maria Ladeira constrói uma reportagem que tem claramente como base dados fornecidos pela Associação Paulista de Medicina, em comemoração ao Dia da Homeopatia. O artigo traz a referência numérica daqueles escritos no ano anterior, que afirmavam a correspondência de 250 homeopatas para 30 milhões de pacientes, mas, por ser um texto de maior fôlego, apresenta outros elementos que contextualizavam a medicina homeopática historicamente, afirmando, entre suas características, ser uma "medicina da natureza". Para afirmar novamente seu distanciamento de práticas não científicas, a autora chama a atenção para o fato de que a homeopatia se afasta do curandeirismo e do espiritismo, ganhando adeptos em várias partes do mundo, citando a França como exemplo (Ladeira, 21 nov. 1973).

Por ocasião do Dia do Homeopata, o Caderno B traz representações da homeopatia como medicina natural, construídas a partir do ponto de vista médico. Dois homeopatas - Vera Lúcia Acar e Cláudio Araújo - foram entrevistados pelo Jornal do Brasil, que também noticia uma palestra proferida por eles no Shopping Cassino Atlântico em 5 de agosto de 1979, intitulada "A homeopatia, uma medicina alternativa?".

Segundo a reportagem, Vera liderava com Cláudio um grupo de estudos em homeopatia. Ela descreve sua trajetória de descoberta da macrobiótica, do naturismo, do vegetarianismo, da acupuntura, iridologia, até chegar à homeopatia. Tecendo críticas aos homeopatas pluralistas e à biomedicina, seu companheiro denunciava o crescente interesse da indústria farmacêutica em se expandir à custa da promoção da doença. Cláudio finalizou a entrevista afirmando: "Hoje o mundo enfrenta toda essa depredação ecológica, mas ao mesmo tempo pinta um aumento pela homeopatia. A mesma terra que produziu Hitler nos deu também um cientista como Hahnemann" (Bahiana, 21 out. 1979). Em comparação com o anterior, esse texto traz elementos que se distanciam um pouco do discurso institucional da homeopatia.

Outra forma de apresentar a homeopatia se construiu por meio de sua utilização por pessoas que não possuíam uma formação acadêmica na área da saúde. Uma reportagem ilustrada, de página inteira, abordava a exposição do artista plástico Roberto Magalhães na Petite Galerie, em Paris, descrevendo-o como "desenhista, pintor, místico, estudioso do Orientalismo". Questionado pelo repórter sobre seu interesse por esoterismo e "medicinas paralelas", entre elas a homeopatia, o artista respondeu que tinha uma grande biblioteca especializada no assunto, mas que não empregava seu conhecimento acerca de medicinas alternativas em outras pessoas: 
eu não sou médico, portanto não tenho o direito de receitar. Os estudos que faço, são em mim. Existem remédios que a ciência oficial despreza, mas que curam muito mais eficazmente do que a própria medicina oficial. Porque eu acho que a arte tem que ser científica como a ciência deve ser filosófica. Tem que haver uma coerência entre uma coisa e a outra. E o que a gente vê no mundo é exatamente o contrário. A ciência não tem filosofia, então ela destrói, mata, envenena (Rangel, 6 ago. 1975).

Essa reportagem revela como as pessoas sem formação acadêmica na área da saúde se interessavam e utilizavam as medicinas alternativas como referência para um autotratamento. Também apresenta um discurso que demonstra a pretensão de alcançar uma união entre a objetividade representada pela ciência e a subjetividade expressa pela filosofia e pela arte. Se o movimento de contracultura buscava se afastar do universo tecnológico que era expressão da ciência, o movimento Nova Era inaugura uma nova relação com o conhecimento científico, no desejo de fusão entre objetivo e subjetivo expresso nas tentativas de criar uma "nova ciência" que incluísse outros parâmetros (D’Andrea, 2000).

As representações da homeopatia construídas por leigos não descartam, mas, antes de tudo, não aderem a uma ciência já estabelecida, como é o caso dos discursos emitidos pelas instituições homeopáticas. Acreditam ser possível a introdução de outras referências e conceitos que foram rejeitados pela ciência médica acadêmica mas que, para eles, são imprescindíveis para a construção do conhecimento e fazem parte da sua visão de mundo.

Uma segunda reportagem com Roberto Magalhães é feita novamente por Maria Lúcia Rangel para o Caderno B do Jornal do Brasil em 1979. Ao apresentar o artista, a repórter ressalta as características esotéricas de seu trabalho, já apresentadas anos antes, e valoriza a narrativa sobre seu envolvimento com medicinas alternativas: "Roberto estudou minuciosamente a homeopatia. Possui ainda uma cristaleira repleta de vidrinhos contendo pós, pílulas, tinturas, além de um arquivo com cada doença ou dor catalogada e seu correspondente homeopático" (Rangel, 14 ago. 1979).

Mesmo não tendo formação acadêmica na área médica, Magalhães não se privava de conhecer e aplicar a homeopatia. Em um espaço muito mais discreto e contido do jornal, um leitor também expunha seus conhecimentos sobre a medicina homeopática, oferecendo seus serviços, caso não tivessem acesso a um médico homeopata, aos pais de um garoto que tinha muito próxima a ameaça de ver amputadas as partes afetadas por uma doença (Nair, 15 set. 1977). Raghavan Pillal Kesavan Nair, o autor da carta, emite mais tarde outra nota no Jornal do Brasil, pois havia recebido muitas ligações telefônicas de outros leitores e se sentia na obrigação de esclarecer que não era médico (Nair, 20 set. 1977).

Certamente, Roberto Magalhães e Raghavan Nair não estavam sozinhos na busca por conhecimento de práticas alternativas de saúde que pudessem promover o autocuidado. O exercício dessas medicinas por pessoas não diplomadas era estimulado por obras que se destinavam a um amplo público e que, provavelmente, faziam parte de um grupo "alternativo" não institucionalizado, dentro das características apontadas por Giddens (2002) a respeito da reflexividade da modernidade. Os livros sobre medicinas alternativas faziam parte desse universo amplo de escolhas, que vemos também presente no Jornal do Brasil. 


\section{A homeopatia nos livros}

A primeira característica das obras selecionadas destinadas ao público leigo que tratam da homeopatia é, paradoxalmente, o reforço do papel do médico como agente de cura. $\mathrm{O}$ livro A cura pelas plantas, pela água e pela homeopatia traz, em sua introdução, a intenção de "auxiliar as famílias brasileiras no conhecimento dos medicamentos homeopáticos, na utilização de ervas e plantas medicinais e também da água", alertando, ao mesmo tempo, que "os casos de doenças agravados pela demora em se usar o remédio devem ser levados imediatamente ao conhecimento dos médicos" (Seabra, s.d.).

No livro homônimo de autoria de Heinrich Weyke (1965), o mesmo teor de objetivo e advertência também é encontrado: "embora muitos tenham a opinião de que qualquer pessoa pode orientar seu próprio tratamento homeopático em qualquer caso, julgamos mais prudente procurar um médico nos casos mais difíceis, isto é, nos de doenças graves". Essa advertência inicial é complementada por outra mais enfática, afirmando que, sempre que possível, o doente deve procurar um médico, tornando o conselho ainda mais ambíguo.

As afirmativas demonstram o cuidado dos autores em não se comprometer junto à corporação médica, mas, ao mesmo tempo, revelam a potencialidade de o material ser usado por leigos, destinando ao médico apenas os casos mais complicados. Ambas as obras reforçam o papel do não médico em promover a cura, seja de si ou de seus próximos, diferentemente da maioria dos discursos encontrados no Jornal do Brasil.

As quatro obras elencadas para esta análise partilham de muitas representações construídas no jornal carioca, como as ideias de uma medicina barata e suave. Porém, o objetivo dessas obras, ao contrário das notícias e reportagens do Jornal do Brasil, não é apenas abordar ou divulgar a homeopatia para um "público paciente", mas formar agentes que empreguem os medicamentos homeopáticos em conjunto com outros recursos "naturais".

Entre as representações já encontradas, a de medicina natural, "suave", está presente em todas as obras, de forma bastante enfática, sendo o ponto principal de atratividade exercido pela homeopatia junto à sua clientela: "os remédios homeopáticos agem suavemente sobre o organismo, de modo que o medicamento não ataca violentamente nenhum órgão ou função; assim, o doente entra em convalescença imediatamente" (Weyke, 1965). O conceito de suavidade estaria relacionado às características de diluição e dinamização, que confeririam ao medicamento a capacidade de promover a "reestruturação dos processos orgânicos normais" e não causar "atividades tóxicas e colaterais" (Bontempo, 1979, p.36-37).

No livro de Bontempo, o conceito de medicina natural se encontra no título e serve para congregar várias outras práticas em saúde, cujo uso conjunto é aconselhado como "ramos terapêuticos": macrobiótica, acupuntura, shiatsu, do-in, homeopatia, fitoterapia e medicina oculta poderiam e deveriam ser utilizadas em conjunto, como recursos complementares (Bontempo, 1979, p.10).

A noção de medicina natural, no livro de Bontempo, foi construída a partir da ideia de leis, já evocada no Jornal do Brasil em relação à homeopatia: "a questão do nome fica resolvida se considerarmos como 'Medicina Natural' a uma medicina que tem esse nome 
não por que usa recursos e técnicas apenas naturais ou porque utiliza medicamentos de origem apenas natural, mas porque estuda e respeita 'leis naturais', identificando-as e empregando-as no Homem" (Bontempo, 1979, p.6). Esse conceito aponta para a afirmação de que essas medicinas - entre as quais a homeopatia está incluída - pertenceriam a uma ciência renovada. Essa ideia é compartilhada pelas outras obras, seja por meio da evocação da lei dos semelhantes, elaborada por Hahnemann, ou afirmando que a "homeopatia constitui atualmente um dos mais adiantados ramos da ciência médica e farmacêutica cada vez mais aceita pelo público devido aos seus excelentes resultados" (Seabra, s.d.).

Em relação ao aspecto conciliatório da homeopatia com a biomedicina, presente em seu processo de construção como um método científico de cura, os livros destinados ao público leigo diferem muito das representações construídas no Jornal do Brasil. Enquanto os dois livros mais antigos tratam da homeopatia como uma especialidade que não é empregada por um médico alheio a essa medicina, pois "nenhum médico lança mão dos processos de cura que não se enquadram dentro da medicina de sua especialidade" (Weyke, 1965, p.10), os dois mais recentes constroem um abismo irreconciliável entre ambas.

O Livro de bolso da medicina natural promove essa diferença com base na crítica à estrutura econômica vigente, responsável, segundo seu autor, pelo condicionamento do cientista "em detrimento da vida humana e da Natureza". Bontempo $(1979$, p.5) afirma que "o cientista hoje não pode abandonar a abordagem racional e analítica e aventurar-se pelo profundo universo da intuição e da dialética, sob pena de ser considerado um autêntico herege". O desprezo por outras medicinas viria dessa exclusão de outras possibilidades de pensamento, sustentadas pela estrutura econômica e o academicismo, que constituiriam o alicerce da biomedicina e seriam irreconciliáveis com outras formas de cura compreensíveis por meio de outros prismas. Porém, Bontempo inclui a tecnologia médica como recurso passível de ser utilizado, como o uso de raios $\mathrm{x}$, antibióticos ou cirurgias em casos extremos, não descartando totalmente a biomedicina, mas também não aderindo aos preceitos alopáticos.

Já Donald Law, ${ }^{3}$ autor da obra mais recente de origem estrangeira, apesar de rememorar a lei dos semelhantes, é mais radical na promoção da cisão entre homeopatia e biomedicina. Ele descreve a homeopatia como "um ramo da arte de curar que fez as pazes com a escola médica ortodoxa, e devido a isto quase sucumbiu. Os primeiros homeopatas eram todos alopatas e a necessidade emocional de unir-se ao mundo médico era forte demais para eles. Em anos recentes surgiu grande número de homeopatas bem treinados e eficientes, que nada têm que ver com os alopatas. Parece que a homeopatia sobreviverá unicamente através destes praticantes solitários" (Law, 1981, p.107).

Embora trate de um contexto que não é brasileiro, Law revela uma posição definida na relação entre homeopatia e biomedicina que distancia definitivamente a primeira da segunda. Chega a afirmar que a homeopatia "pouco tem para aprender com a prática médica oficial" (Law, 1981, p.109) e demonstra isso quando define a doutrina homeopática e seu embasamento na noção de força vital, sem a qual se tornaria impossível compreender suas peculiaridades.

Enquanto Weyke e Seabra sequer referenciam a força vital em seus textos de apresentação da homeopatia, Bontempo $(1979$, p.34) a denomina "energia vital" e a atribui à corrente 
vitalista à qual pertenceria a homeopatia. Já para Law, esse é um ponto de não reconciliação da medicina homeopática, tanto que seu livro, denominado Guia da medicina alternativa, estaria mais próximo de uma definição da homeopatia como medicina alternativa.

\section{Considerações finais}

Analisando a trajetória da homeopatia, Madel Luz (1996, p.287-89) procura definir quem era sua clientela na década de 1970. Ela aponta para sua diversidade, localizando a camada popular como consumidora da homeopatia em centros de umbanda e centros espíritas, e as classes médias empobrecidas, compostas por estudantes e professores universitários, funcionários públicos, técnicos, e as classes médias altas, como intelectuais, artistas, estudantes, comerciantes, tecnocratas aderindo "ideologicamente" à homeopatia. As classes médias empobrecidas, incapacitadas de pagar pelos serviços médicos (inclusive homeopatas), teriam sido responsáveis por construir a homeopatia como medicina alternativa, e as classes médias altas teriam incluído a medicina de Hahnemann no conjunto de produtos da Nova Era. Por fim, haveria uma classe rica consumidora da homeopatia, que incluiria empresários, artistas, profissionais liberais.

Embora seja plausível que o público do Jornal do Brasil e de seu Caderno B ou de livros classificados como "esotéricos" ou "naturalistas" tenha sido composto por uma categoria de pessoas pertencentes a um círculo mais intelectualizado da sociedade brasileira, não é possível traçar uma classificação precisa desse coletivo. Retomando Marcos Queiroz (2003, p.127) em seu estudo sobre a inserção da homeopatia, acupuntura e fitoterapia no estado de São Paulo, uma "clivagem de classe" não atende à categorização da clientela das medicinas alternativas.

Os adeptos da homeopatia na década de 1970 parecem partilhar das ideias que fomentaram os movimentos de contracultura e Nova Era, mas são diferentes e ecléticos entre si, possuindo pontos de convergência e divergência. Vale a pena ressaltar que ideais da contracultura e da Nova Era se transformaram em produtos de consumo que foram incorporados à sociedade capitalista, incluindo-se aí aqueles destinados a manter ou recuperar a saúde.

À medida que avançamos na década de 1970, ao mesmo tempo que nos aproximamos da oficialização da homeopatia como especialidade da biomedicina, parece crescer, tanto nos discursos veiculados pelo jornal quanto aqueles presentes nos livros, sua representação como uma medicina alternativa. O caráter alternativo não se situa apenas na terapêutica homeopática, que poderia ser uma opção econômica mais viável: tal conceito colocaria em valor dimensões subjetivas do ser humano e se distanciaria de explicações materialistas que davam suporte às representações apoiadas pelas instituições homeopáticas, importantes para sua entrada no universo institucional e legalizado da biomedicina. Para esses usuários da homeopatia, que compartilhavam de concepções do universo contracultural, escolhê-la como alternativa parece refletir a busca por caminhos diferentes que não excluíssem as dimensões subjetivas e não materiais da construção do conhecimento. 


\section{NOTAS}

${ }^{1}$ A partir da década de 1990, o sociólogo britânico Anthony Giddens concentra seus estudos sobre as sociedades ocidentais a partir da década de 1960, concebendo-as não como diferentes da sociedade moderna, mas em uma modernidade que se aprofunda, radicaliza-se. Nesse contexto, a radicalização da modernidade se traduz pelas experiências cotidianas dos indivíduos, em especial por meio de suas relações consigo e com os próximos, construindo suas identidades (Nizet, 2007).

${ }^{2}$ Disponível em: <http://www.guiadosquadrinhos.com/gibis-da-editora/o-livreiro/386>. Acesso em: 22 mar. 2018.

${ }^{3}$ Cabe ressaltar que, durante as décadas de 1970 e 1980, vários foram os autores estrangeiros que escreveram a respeito de alimentação e medicina alternativas traduzidos no Brasil, indicando forte influência de outros países, principalmente EUA, na formação de conceitos sobre medicinas alternativas em nosso país. Essas considerações fazem parte do projeto de pesquisa "Livros para uma nova consciência": as medicinas alternativas e marginais e a editora Ground, desenvolvido no Departamento de História da Universidade Federal de Santa Catarina.

\section{REFERÊNCIAS}

AGROBIOLOGIA...

Agrobiologia, a alquimia do século XX. Jornal do Brasil, Caderno B, p.10. 23 abr. 1975.

ALMEIDA, Maria Hermínia Tavares de; WEIS, Luiz. Carro zero e pau de arara: o cotidiano da oposição de classe média ao regime militar. In: Schwarcz, Lilia Moritz (Org.). História da vida privada no Brasil. v.4. São Paulo: Companhia das Letras. p.321-405. 1998.

ANDRADE, João Tadeu de.

Medicina alternativa e complementar: experiência, corporeidade e transformação. Salvador: Edufba; Educe. 2006.

ASSOCIAÇÃO...

Associação promove a medicina do Rio em congresso nacional. Jornal do Brasil, p.10. 8 out. 1973.

BAHIANA, Ana Maria.

Quem - Vera busca a cura pelo equilíbrio. Jornal do Brasil, Revista de Domingo, p.4. 21 out. 1979.

BARROS, Nelson Felice de.

Medicina complementar: uma reflexão sobre o outro lado da prática médica. São Paulo: Annablume; Fapesp. 2000.

BONTEMPO, Marcio.

Livro de bolso da medicina natural. São Paulo: Ground. 1979.

BRASIL...

Brasil tenta fabricar já vacina contra meningite. Jornal do Brasil, p.12. 27 jul. 1974.

CARVALHO, Cesar Augusto de.

Viagem ao mundo alternativo: a contracultura nos anos 80. São Paulo: Unesp. 2008.

CURSOS...

Cursos: acupuntura. Jornal do Brasil, Caderno B, p.2. 26 maio 1979.
D'ANDREA, Anthony A.F.

O self perfeito e a Nova Era. São Paulo: Loyola. 2000.

DUNN, Christopher.

Contracultura: alternative arts and social transformation in authoritarian Brazil. Chapel Hill: University of North Carolina Press. 2016.

EMPRESA...

Empresa de jovens usa talento como capital. Jornal do Brasil, Caderno Turismo, p.3. 23 ago. 1973.

FAURE, Olivier.

L'homéopathie entre contestation et intégration. Actes de la Recherche en Sciences Sociales, n.143, p.88-96. 2002-2003.

FERREIRA, Álvaro, Homeopatia. Jornal do Brasil, Seção de Cartas, p.6. 3 ago. 1974.

GIDDENS, Anthony.

Modernidade e identidade. Rio de Janeiro: Zahar. 2002.

HERZLICH, Claudine.

Santé et maladie: analyse d'une représentation sociale. Paris: EHESS. 2005.

HOMEOPATAS...

Homeopatas instalam congresso. Jornal do Brasil, p.18. 16 out. 1979 .

HOMEOPATAS..

Homeopatas recomendam preventivo. Jornal do Brasil, p.13. 3 ago. 1974.

HOMEOPATIA...

Homeopatia espera que em 73 seja especialidade normal para a medicina. Jornal do Brasil, p.21. 23 nov. 1972.

HOMEOPATIA...

Homeopatia fará 132 anos promovendo congresso que irá até Dia do Homeopata. Jornal do Brasil, p.14. 18 nov. 1972. 
HOMEOPATIA...

Homeopatia só tem 250 atendendo 30 milhões. Jornal do Brasil, p.7. 6 nov. 1972.

HOMEOPATIA...

Homeopatia busca medida oficial que a consolide como um ramo da medicina. Jornal do Brasil, p.31. 14 set. 1970.

JOVCHELOVITCH, Sandra.

Os contextos do saber: representações, comunidade e cultura. Petrópolis: Vozes. 2011.

JUSTO, Célia Maria Patriani; GOMES, Mara H. de Andréa.

A cidade de Santos no roteiro de expansão da homeopatia nos serviços públicos de saúde do Brasil. História, Ciências, Saúde - Manguinhos, v.14, n.4, p.1159-1171. 2007.

LADEIRA, Célia Maria.

Homeopatia, a lei natural de cura. Jornal do Brasil, p.10. 21 nov. 1973.

LAVRAS, Carmen.

Atenção primária à saúde e a organização de redes regionais de atenção à saúde no Brasil. Saúde e Sociedade, v.20, n.4, p.867-874. 2011.

LAW, Donald.

Guia de medicina alternativa. São Paulo:

Brasiliense. 1981.

LIMA, Patrícia Ferreira de Souza.

Caderno B do Jornal do Brasil: trajetória do segundo caderno na imprensa brasileira (196085). Tese (Doutorado em História Social) - Instituto de Filosofia e Ciências Sociais, Universidade Federal do Rio de Janeiro, Rio de Janeiro. 2006.

LUZ, Madel.

Medicina e racionalidades médicas:

estudo comparativo da medicina ocidental contemporânea, homeopática, tradicional chinesa e ayurvédica. In: Canesqui, Ana Maria (Org.). Ciências sociais e saúde para o ensino médico. São Paulo: Fapesp. p.181-200. 2000.

LUZ, Madel T.

A arte de curar versus a ciência das doenças: história social da homeopatia no Brasil. São Paulo: Dynamis. 1996.

MAGNANI, José Guilherme C.

O Brasil da Nova Era. Rio de Janeiro: Zahar. 2000.

MAGNANI, José Guilherme C.

Mystica urbe. São Paulo: Studio Nobel. 1999.

MARCUSE, Herbert.

Eros e civilização: uma interpretação filosófica do pensamento de Freud. Rio de Janeiro: LTC. 2010.

MENINGITE...

Meningite matou 214 este mês em São Paulo e doentes são 1.782. Jornal do Brasil, p.11. 26 ago. 1974.

MONNEYRON, Frédéric; XIBERRAS, Martine.

Le monde hippie: de l'imaginaire psychédélique à la révolution informatique. Paris: Imago. 2008.

NAIR, Raghavan Pillal Kesavan.

Homeopatia. Jornal do Brasil, p.10. 20 set. 1977.

NAIR, Raghavan Pillal Kesavan.

Homeopatia. Jornal do Brasil, p.2. 15 set. 1977.

NIZET, Jean.

La sociologie de Anthony Giddens. Paris: La

Découverte. 2007.

PREVIDÊNCIA..

Previdência estuda pedido para incluir

homeopatia em seus serviços médicos. Jornal do Brasil, p.9. 9 out. 1977.

QUEIROZ, Marcos S.

Saúde e doença: um enfoque antropológico.

Bauru: Edusc. 2003.

RANGEL, Maria Lúcia.

Roberto Magalhães, uma cabeça desdobrada em várias. Jornal do Brasil, Caderno B, p.10. 14 ago. 1979.

RANGEL, Maria Lúcia.

Roberto Magalhães: com a arte esotérica, o Brasil será a capital cultural do mundo. Jornal do Brasil, Caderno B, p.10. 6 ago. 1975.

RISÉRIO, Antonio et al.

Anos 70: trajetórias. São Paulo: Itaú Cultural;

Iluminuras. 2005.

ROSZAK, Theodore.

A contracultura. Petrópolis: Vozes. 1972.

SEABRA, Armando.

A cura pelas plantas, pela água e pela homeopatia. São Paulo: O Livreiro. s.d.

SENSACIONAL...

Sensacional para você que gosta, pratica, assiste, dirige ou ensina esportes! Placar, n.384, p.41. 2 set. 1977.

SIGOLO, Renata Palandri.

Nilo Cairo e o debate homeopático no início do século XX. Curitiba: UFPR. 2012.

WEBER, Beatriz Teixeira.

Estratégias homeopáticas: a Liga Homeopática do Rio Grande do Sul nos anos 1940-1950.

História, Ciências, Saúde-Manguinhos, v.18, n.2, p.291-302. 2011.

WEYKE, Heinrich.

A cura pelas plantas, pela água e pela homeopatia. São Paulo: Edições e Publicações Brasil. 1965. 